Sharif University of Technology
Scientia Iranica
SCIENTIA
I RAN I CA

Invited/Review Article

\title{
Neurocomputing in civil infrastructure
}

\section{J.P. Amezquita-Sanchez ${ }^{\mathrm{a}, *}$, M. Valtierra-Rodriguez ${ }^{\mathrm{a}}$, M. Aldwaik ${ }^{\mathrm{b}}$ and H. Adeli ${ }^{\mathrm{b}}$}

a. Faculty of Engineering, Departments of Electromechanical, Civil, and Biomedical Engineering. Autonomous University of Queretaro, Campus San Juan del Rio, Moctezuma 249, Col. San Cayetano, 76807, San Juan del Rio, Queretaro, Mexico.

b. Department of Civil, Environmental, and Geodetic Engineering, The Ohio State University, 470 Hitchcock Hall, 2070 Neil Avenue, Columbus, OH 43220, U.S.A.

Received 30 October 2016; accepted 12 November 2016

\author{
KEYWORDS \\ Artificial neural \\ networks; \\ Civil structures; \\ System identification; \\ Structural health \\ monitoring; \\ Control; \\ Prediction; \\ Optimization; \\ Construction; \\ Geotechnical.
}

\begin{abstract}
This article presents a review of the recent applications of Artificial Neural Networks (ANN) for civil infrastructure including structural system identification, structural health monitoring, structural vibration control, structural design and optimization, prediction applications, construction engineering, and geotechnical engineering. The most common ANN used in structural engineering is the backpropagation neural network followed by recurrent neural networks and radial basis function neural networks. In recent years, a number of researchers have used newer hybrid techniques in structural engineering such as the neuro-fuzzy inference system, time-delayed neuro-fuzzy inference system, and wavelet neural networks. Deep machine learning techniques are among the newest techniques to find applications in civil infrastructure systems.
\end{abstract}

(C) 2016 Sharif University of Technology. All rights reserved.

\section{Introduction}

Artificial Neural Networks (ANNs) are powerful mathematical models inspired by interconnected neurological structure of the human brain to learn and solve problems through pattern recognition [1-3]. They have been used to solve complicated pattern recognition and classification problems in numerous applications such as image and object recognition [4], fingerprint analysis [5], video analysis [6], power quality analysis [7], computer vision [8], biomedical and medical applications [9], neuroscience [10,11], control engineering [12], computer security [13], GPS data analysis [14], air traffic control [15], and financial application [16].

Adeli and Yeh [17] introduced the first application of ANNs in civil engineering published in any

*. Corresponding author.

E-mail addresses: jamezquita@uaq.mx (J.P.

Amezquita-Sanchez); adeli.1@osu.edu (H. Adeli) journal. Since then, many techniques and methodologies based on ANNs have been employed in the civil engineering discipline for optimization, control, identification, and prediction problems, among others. Adeli [18] presented a review of applications of ANNs in civil engineering published in the period 1989 to 2001. This article presents a review of the recent applications of ANNs for civil infrastructure including structural system identification, structural health monitoring, structural vibration control, structural design and optimization, prediction applications, construction engineering, and geotechnical engineering.

\section{Structural system identification}

Structural System Identification (SSI) is an important topic in modern structural engineering [19,20]. The aim of SSI is to develop a mathematical model for a structural system based on a set of inputs and corresponding output measurements $[21,22]$. 
ANNs can be used to estimate a learning model based on a set of input-output measurements in order to identify a structural system. Huang et al. [23] employed a back-propagation neural network for modeling and identifying the dynamic characteristics of a building during strong earthquakes. They used a fivestory frame subjected to different strengths of the Kobe earthquake to validate the feasibility and reliability of the method for estimating the changes in structural response under different levels of earthquakes. Hung et al. [24] noted that the implementation of ANNs in SSI suffers from the lack of an efficient constructive method for approximating nonlinear systems as found in largestructures, as well as the problems of local minima and convergence efficiency.

Zhang and Benveniste [25] proposed the combination of wavelet transform [26-27] and neural networks, called Wavelet Neural Network (WNN), as a method to approximate arbitrary nonlinear functions. WNN has been used and adapted by a number of researchers for SSI of civil infrastructure in the past two decades. Hung et al. [24] used the WNN for nonparametric identification of a five-story test frame subjected to simulated seismic loadings on a shake table and reported a maximum error of $28 \%$ with reduced training efforts for the WNN compared with the standard ANN.

Adeli and Jiang [28] observed that the WNN method for SSI also suffers from: 1) lack of an efficient constructive model; 2) the need for calibration of its parameters by trial and error; 3 ) the dependency of the results on noise contained in the signal; and 4) poor identification accuracy when measured data include imprecision, which is often the case. To overcome these limitations, Adeli and Jiang [28] presented a novel multi-paradigm dynamic time-delay fuzzy WNN model for nonparametric identification of civil structures using the nonlinear autoregressive moving average with exogenous input model through adroit integration of wavelets, chaos theory, and two computational intelligence techniques, neural networks, and fuzzy logic. Further, they presented an adaptive LevenbergMarquardt-least squares algorithm with a backtracking inexact linear search scheme for training the model. The proposed model was validated using two high-rise building structures: a twelve-story and a twenty-story steel frames. The results showed that the proposed approach is efficient for modeling large-scale structures with nonlinear and noise-contaminated measurements of structural response under extreme loadings. In all cases, they reported a maximum error of less than about $3 \%$, and concluded that this approach can help structural engineers design more effective earthquakeresistant structures [29].

In their seminal book, Adeli and Hung [30] demonstrated adroit integration of the three compu- tational intelligence computing paradigms: neural networks, fuzzy logic, and evolutionary computing; they can solve complicated pattern recognition problems more effectively than either one of them individually. Since then, a large number of articles have been published on hybridization of these methods such as neuro-fuzzy algorithms [31]. Wang and Shi [32] used an Adaptive Neuro-Fuzzy Inference System (ANFIS) for identification of Magneto-Rheological (MR) dampers. It is capable of approximating nonlinear systems, but is computationally intensive requiring significant computational resources. To overcome this shortcoming, Mitchell et al. [33] integrated the wavelet transform with ANFIS to create WANFIS to approximate the nonlinear behavior of a three-story building equipped with an MR fluid damper subjected to four different earthquakes: El-Centro earthquake, Kobe earthquake, Hachinohe earthquake, and Northridge earthquake. They reported the results with a maximum error of $23 \%$. In recent years, MR dampers have been advocated as an effective tool for semi-active control of structures.

Arsava et al. [34] presented a Time-delayed Adaptive Neuro-Fuzzy Inference System (TANFIS) for approximating the behavior of a cantilever aluminum plate beam equipped with nonlinear MR dampers and subjected to impact loads. Zhou et al. [35] presented a response surface method based on Radial Basis Functions (RBF) for model-updating of cable-stayed bridges. Khalid et al. [36] presented a dynamic Recurrent Neural Network (RNN) [37] for nonlinear hysteretic identification of a small-scale MR damper.

Sun et al. [38] presented a statistical Bayesian inference-based regularization method for identification of structural parameters and external loadings using state space models. They applied the model to a 6DOF shear type building and a 15-bar truss bridge. Recently, Perez-Ramirez et al. [39] presented a novel methodology for modal parameters identification of civil structures using Random Decrement Technique (RDT), Synchrosqueezed Wavelet Transform (SWT), the Hilbert Transform (HT), and the Kalman Filter (KF). The effectiveness of the proposed approach was first validated using numerical and experimental data of a benchmark 4-story steel frame subjected to ambient vibrations. The methodology was then employed to determine the natural frequencies and damping ratios of a real-life bridge. Their results showed accurate identification of the natural frequencies and damping ratios even when the signal is embedded in high-level noise. Perez-Ramirez et al. [40] presented a stateof-the-art review of the time-frequency techniques for modal parameters identification of civil structures from acquired dynamic signals and the factors affecting their estimation accuracy. 


\section{Structural health monitoring}

Civil infrastructure is susceptible to damage and deterioration during its service life. SHM is an emerging technology that can be utilized for early damage detection and reliability assessment of the structure and to take remedial measures to improve public safety.

In the last two decades, ANNs have been used as an important tool for SHM of civil structures with the feedforward architecture, which is the most commonly used [41]. Hung and Kao [42] showed that the optimal weights of the approximating artificial neural networks can be used to detect structural damage. They trained two ANNs: one to determine undamaged and damaged states and the other to locate the damage. Sun and Chang [43] decomposed the energies of signals using wavelet packet transform [44] and used them as inputs into an ANN for damage assessment. They noted that the energies are sensitive to structural damage, and therefore can be used to identify damage occurrence, location, and severity. Lee et al. [45] presented an ANN method for damage detection in bridges where the modal properties are used as discriminant features.

Fang et al. [46] proposed the use of Frequency Response Functions (FRFs) as input data to train a backpropagation neural network to detect and locate damage in a cantilevered beam subjected to harmonic excitations applied at the tip of the beam. Lam et al. [47] used measured Ritz vectors and a multilayer perceptron ANN to detect, locate, and quantify the severity of damage in a $2 \mathrm{D}$ truss structure subjected to forced excitations. Ni et al. [48] presented seismic damage identification using a combination of Principal Component Analysis (PCA), FRF, and a multilayer perceptron ANN and the test results on the scaled model of a 38-story RC structure. Xu and Humar [49] used a feedforward ANN to detect, locate, and quantify damage severity in the Crowchild Bridge located at northwest Calgary, Alberta. Energy was used as inputs to train the neural network for damage detection. Mehrjoo et al. [50] used a multilayer perceptron ANN to detect, locate, and quantify damage severity in the joints of two truss bridge structures subjected to dynamic excitations. The natural frequencies and mode shapes of structures were used as inputs to train the ANN for damage detection.

Similar to the work proposed by $\mathrm{Ni}$ et al. [48], $\mathrm{Li}$ et al. [51] employed the FRF-PCA-ANN approach for monitoring the health condition of a beam subjected to forced excitations. The authors observed that results are susceptible to noise, producing errors in the quantification of the damage severity, and location of the damage in the beam. Similar methodologies were proposed by Samali et al. [52] for damage detection in a two-story frame structure subjected to forced excitations. Other applications of multilayer percep-

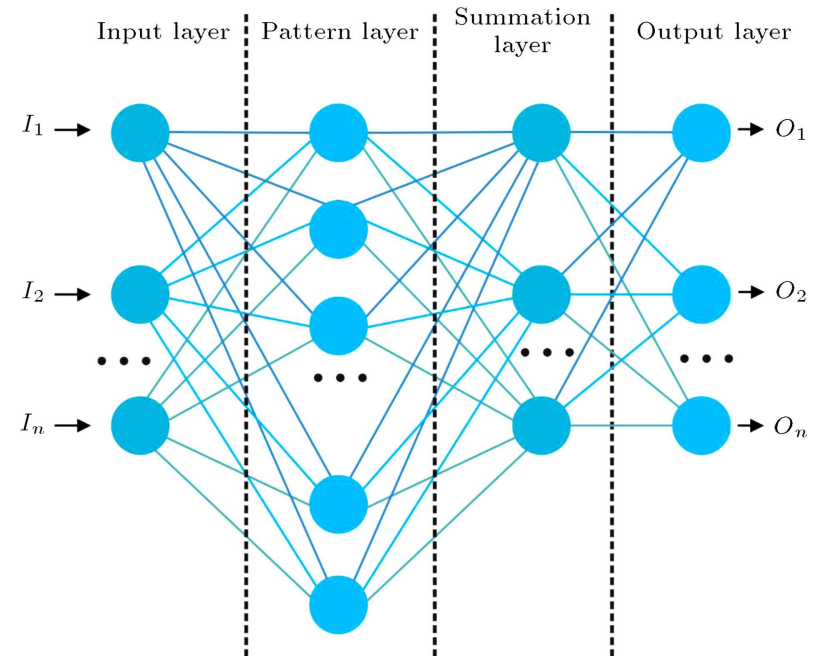

Figure 1. Architecture of a probabilistic neural network.

tron ANN tested under noisy signal were presented by Garcia-Perez et al. [53] and Shu et al. [54] for monitoring the health condition of a 3D truss-type structure subjected to forced excitations and a railway bridge model subjected to dynamic excitations produced by a train.

Probabilistic Neural Network (PNN), another feedforward architecture based on the probabilistic Bayesian criteria has gained attention in SHM in recent years. It presents a relatively quick training speed, good network fault tolerance, and strong pattern classification ability compared with the multilayer perceptron [55]. Figure 1 shows a typical architecture of PNN. It consists of an input layer, a pattern layer, a summation layer, and the output layer. Jiang et al. [56] used PNN to detect and locate single- and multidamage patterns in a 2D 7-storey steel frame. Damage scenarios were simulated by reduction of the stiffness in each story unit. Zhou et al. [57] discussed damage localization of Tsing Ma cable-supported bridge using modal frequency data and PNN with an accuracy of $85 \%$. Butcher et al. [58] discussed defect detection in reinforced concrete using random neural architectures.

Story and Fry [59] used a competitive array of neural networks to detect damage in a 100-year old railroad drawbridge. Farrokh et al. [60] modeled the hysteretic behavior with and without degradation in frames using a generalized Prandtl neural network. Dai et al. [61] used a multiwavelet neural networkbased method to detect damage in a 2D truss structure subjected to dynamic excitations.

The great majority of the published SHM papers deal with small or academic exercises as noted in the previous paragraphs. Transferring the SHM technology from academic examples to large real-life structures represents a number of challenges such as the rather large number of sensors needed and inordinate amount of data collected. The problem is akin to finding a nee- 
dle in a haystack. An approach for SHM of large civil structures was proposed by Jiang and Adeli [62]. They presented a damage detection methodology through integration of the wavelet transform, ANN, fuzzy logic, and the multiple signal classification (MUSIC) method and verified the matter by applying it to damage identification of the scaled model of a 38-story reinforced concrete structure subjected to synthetic seismic excitations. Fuzzy logic was used to model the imprecision in the model. The results showed that the proposed approach is effective for distinguishing a healthy structure from a damaged structure and quantifying the damage severity broadly such as minor, moderate, or severe. Therefore, it can be used as a powerful tool for real-time health monitoring and nondestructive damage evaluation of large civil structures. Inspired by the work of Jiang and Adeli [62], OsornioRios et al. [63] used the MUSIC-ANN analysis to locate structural damage in a truss-type structure subjected to vibrations.

\section{Structural control}

In the last two decades, a significant amount of research has been published on semi-active and active vibration control of civil structures [64]. Brown and Yang [65] used an ANN for multi-objective active vibration control of a simple lumped-mass beam model. Jha and He [66] employed a multilayer-perceptron ANN to control vibrations of a cantilever beam subjected to forced excitations. Madan [67] used a counter-propagation neural network for active earthquake-induced vibration control of eight-story building structures. Similar research was reported by Kim and Lee [68], Wang and Liao [69], and $\mathrm{Xu}$ and Guo [70] on the use of ANN for active vibration control of structures. The aforementioned works are concerned about ANN-based control of mostly small structural systems.

In recent years, research articles have been published on development of new hybrid approaches for active and semi-active vibration control of large structures. Jiang and Adeli [71] proposed a nonlinear control model for active vibration control of large multi-story structures through integration of two soft computing techniques, ANN and fuzzy logic, and wavelets. They created a dynamic fuzzy wavelet neuroemulator and applied it to a twelve-story building structure with vertical setbacks and an eight-story building structure with plan irregularity.

Recently, other works have been published on active vibration control of large structures using WNN. Figure 2 shows a typical architecture of WNN. It is similar to the feedforward ANN architecture; however, in the hidden layers, a wavelet is used as activation function. Laflamme et al. [72] implemented a WNNbased control algorithm for vibration control of a 39- story office tower located in Boston subjected to wind loading. The structure was equipped with MR fluid dampers on every other story from the 5th floor to the 34th floor. The Mexican hat wavelet was used in the neurocontroller. The authors reported a significant acceleration reduction compared with a traditional feedforward ANN.

Wang and Adeli [73] presented an adaptive control algorithm for nonlinear vibration control of large structures subjected to dynamic loading. It is was on integration of a self-constructing WNN developed specifically for functional approximation of the nonlinear behavior of large structures with an adaptive fuzzy sliding mode control approach. A fuzzy compensation controller was used to reduce the chattering phenomenon encountered in the sliding mode control. They tested the algorithm on a seismically excited continuous cast-in-place prestressed concrete boxgirder highway bridge benchmark problem provided in Agrawal et al. [74].

Hashemi et al. [75] proposed a WNN algorithm for semi-active control of a nine-story building structure equipped with MR dampers. In order to enhance the building performance by minimizing its response, the parameters of WNN were optimized using a Genetic Algorithm (GA) [76]. The efficiency of the proposed method was compared with a feedforward ANN, a linear quadratic Gaussian controller, a clipped optimal controller, and a GA and fuzzy inference-based controller.

\section{Design and optimization}

The Load Factor Design (LFD)-based rating of steel bridges requires a detailed description of the steel

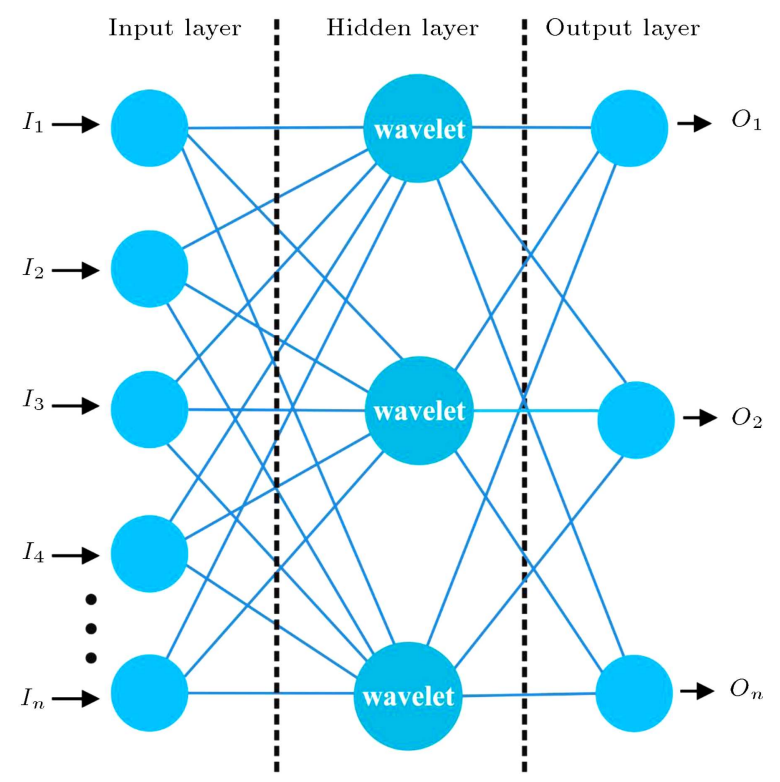

Figure 2. Architecture of a wavelet neural network. 
girder's geometric properties that may not be available for bridges rated on the older Working Stress Design (WSD). Sirca and Adeli [77] presented a counterpropagation ANN for estimating the section properties of steel bridge girders. The result of this research is used in an intelligent decision support system to help bridge engineers convert a WSD-based bridge rating to the LFD-based rating.

Design optimization by its very nature is iterative; in structural design optimization, it usually means a structural analysis in every iteration. A large number of structural analyses can make optimization of large structures computationally expensive and impractical on standard workstations. As such, researchers have proposed schemes for approximate reanalysis. Jenkins [78] proposed structural reanalysis using a neural network-based iterative method. Garzón-Roca et al. [79] used an ANN to estimate the axial behavior of brick masonry walls in the design or assessment of brick masonry walls as a function of four parameters: load eccentricity, slenderness ratio, stiffness, and tensile strength.

One of the first applications of ANN in optimization of civil structures was presented by Adeli and Park [80] who developed a neural dynamic model for optimization of large civil structures through adroit integration of Lyapunov stability theorem, a penalty function method, Kuhn-Tucker conditions, and neural dynamic concepts. The Lyapunov function is used to guarantee that the solution for the dynamic system maintains the equilibrium point without increasing the objective function value. The model was subsequently patented and applied to high-rise and super high-rise building structures including a 144-story super highrise building structure [81]. Employing the neural dynamics model of Adeli and Park [80], Tashakori and Adeli [82] presented a method for optimization of space structures made of cold-formed steel. This is a complicated nonlinear optimization problem because an effective reduced area needs to be calculated for each member in compression as a function of the compressive stress and its width-to-thickness ratio to take into account the nonuniform distribution of stresses in thin cold-formed shapes due to torsional/flexural buckling. The resulting constraints are implicit, nonsmooth, and discontinuous functions of design variables. They presented several examples of minimum weight design of space truss roof structures used in commercial buildings and canopies including one with 432 nodes and 1548 members. Amini and Tavassoli [83] trained an ANN for optimization of control force and the number and location of controllers in a vibration control system.

Some authors presented research on hybridization of ANN with other computational intelligence techniques such as GA and fuzzy logic with the goal of improving the accuracy, efficiency, or stability of the algorithm. Salajegheh and Gholizadeh [84] combined GA with ANN for finding the optimal weight of a 25-bar 3D space tower and a 1300-bar grid space dome. The authors reported that the use of ANN improves the convergence speed of the GA for large structures. Gholizadeh et al. [85] combined GA with a wavelet radial basis function neural network for weight minimization of a 10-bar aluminum truss and a 200-bar steel double layer grid. Salajegheh and Heidari [86] presented the use of WNN and filter banks for optimum design of structures under earthquake excitations. Lagaros et al. [87] utilized an evolutionary algorithm to tackle seismic reliability-based size and topology optimization of a seven-story steel frame using a backpropagation ANN. Salajegheh et al. [88] discussed optimal design of a 120-bar geometrically nonlinear space truss using an Adaptive Neuro-Fuzzy Inference System (ANFIS). Dai and Wang [89] presented an adaptive wavelet frame neural network method for efficient reliability analysis. Similar works were presented by Lee and Shin [90] and de Santana Gomes and Beck [91].

Gholizadeh and Mohammadi [92] combined particle swarm optimization [93-95], bat algorithm, and wavelet backpropagation neural networks for reliability-based seismic optimization of steel momentresisting frames. They applied the model to a threestory steel frame.

\section{Prediction applications}

The goal of a prediction task is to learn about the features or conditions about the future behavior of a dynamic system where ANN has been shown to be a useful tool. In general, application of prediction algorithms and methodologies in civil engineering has focused on two main topics. The first one is related to the prediction of certain features of a project such as cost, strength, safety, functionality, accuracy, or durability, among others. The other is the prediction of damage or deterioration conditions of an infrastructure during its service life in order to avoid or minimize the negative consequences.

ANN has been proposed for prediction of compressive and shear strength of reinforced concrete. Lee [96] used a modular neural network for predicting the concrete strength. Kim et al. [97] used the probabilistic neural networks for prediction of concrete strength based on mix proportions. Gupta et al. [98] presented a neural-expert system for prediction of concrete strength based on concrete mix design, size and shape of specimen, curing technique and period, among others. Pham and Hadi [99] predicted stress and strain in Fiber Reinforced Polymer (FRP)confined square and rectangular columns using ANN. 
They reported an estimation error of less than $5 \%$. Recently, Rafiei et al. [100] presented a comprehensive review of neural network, machine learning, and evolutionary approaches for concrete material characterization.

Panakkat and Adeli [101] presented a review of research on earthquake prediction including applications of neural networks. Panakkat and Adeli [102] presented neural network models for earthquake magnitude prediction using multiple seismicity indicators. They [103] also presented an RNN for approximate earthquake time and location prediction. Adeli and Panakka [104] presented a probabilistic neural network for earthquake magnitude prediction. Alavi and Gandomi [105] combined ANN with Simulated Annealing (SA) to predict the peak time-domain characteristics of strong ground motions such as peak ground acceleration, peak ground velocity, and peak ground displacement based on earthquake magnitude, earthquake source to site distance, average shear-wave velocity, and faulting mechanisms.

Performance, loading capacity, and costs are among important considerations in civil engineering projects. Brown et al. [106] used the LevenbergMarquardt backpropagation neural network for structural response prediction and control. Fall et al. [107] used ANN for prediction of stability and performance of an active aluminum panel structure under uncertainty conditions. Dahou et al. [108] used a multi-layer perceptron to model steel-concrete bond and predicted the ultimate pull-out load. Petroutsatou et al. [109] used a multilayer feed-forward neural network and a general regression neural network to predict the construction costs of a road tunnel. They reported the latter yields better results in most cases.

de Lautour and Omenzetter [110] used ANN to predict seismic-induced structural damage in $2 \mathrm{D}$ reinforced concrete frames based on the variation of structural properties such as stiffness, strength, and damping. Zhang et al. [111] used ANN and cellular automata for predicting the cracking pattern of masonry walls. Al-Rahmani et al. [112] used ANN to predict the most probable cracking pattern in bridge girders. Elshafey et al. [113] estimated the crack width in thick concrete elements using RBF neural network.

Other schemes of neural networks have been also presented for prediction tasks. Zhang and Zhang [114] used an RBF neural network for the prediction of interference effects in buildings caused by other adjacent buildings under wind loading. Lee et al. [115] presented a methodology for prediction of long-term deterioration in bridge elements using a recurrent neural network. Freitag et al. [116] also used an RNN and fuzzy logic for predicting uncertain time-dependent structural responses.

\section{Construction engineering}

Patel and Jha [117] used a feedforward backpropagation ANN to predict safety climate in a construction project. Ten basic requirements of safety climate in construction projects are used as inputs, and the safety climate measure of the project is the output. Training data is based on analysis of more than 250 questionnaires surveyed across the country. Sensitivity analysis revealed that management commitment, supervisory environment, appraisal of physical work environment, work hazard, and providing training and skill development to workers have significant roles on safety climate. They also found that employees' involvement and competence have less influence on safety climate.

Heravi and Eslamdoost [118] also used a feedforward backpropagation ANN for measuring and predicting labor productivity in construction projects in developing countries. Labor productivity is studied in the concrete work of gas, steam, and combined cycle power plant construction projects in Iran. The model found that labor competence, poor decision making, motivation of labor, suitable site layout, and proper planning are the most influential factors in labor productivity. They noted that their work is only a start to better and more in-depth studies for predicting labor productivity.

Deep machine learning techniques [119] are among the newest techniques to find applications in civil engineering. Predicting the price of housing is of paramount importance for near-term economic forecasting of any nation. Recently, Rafiei and Adeli [120] presented a novel model for predicting the price of new housing in any given city at the design phase or beginning of the construction through integration of a deep belief restricted Boltzmann machine and a unique non-mating genetic algorithm. The model can be used by construction companies to calculate the sale market before they start a new construction.

\section{Geotechnical engineering}

Tarawneh [121] presented a backpropagation ANN model to predict pipe pile setup using 104 data points to train the model. The author reported that the model can predict the settlement of piles with $96 \%$ accuracy outperforming the empirical formulas commonly used. Sensitivity analysis indicated that the inputs with the most significant effect on the pipe pile setup are pile diameter, pile length, soil type, the average effective stress at tip, and time.

Araei [122] proposed a backpropagation multilayer perceptron neural network to model the mechanical behavior of angular and rounded rockfill materials including deviator stress, axial strain, and volumetric 
strain. Data from 82 drained triaxial tests were used to train the model. Their results indicated that the trained ANNs are capable of accurately simulating and generalizing the complex mechanical behavior of rockfill materials and can be used to simulate artificial triaxial tests under similar conditions without the need for complicated and time-consuming laboratory experiments.

Shahin [123] presented an RNN for prediction of the full load-settlement response of drilled shafts (bored piles) subjected to axial loading. The model was trained using existing pile load-settlement tests and Cone Penetration Test (CPT) data. It works well interpolating data, but when data outside the training range are presented, prediction accuracy decreases. This can be improved by updating the model using new training examples of wider ranges as new data become available.

\section{Conclusions}

During the last two decades, ANNs have played an important role in structural engineering research. This paper presented an overview of recent applications of ANNs in structural system identification, structural health monitoring, structural vibration control, design and optimization and, prediction applications, construction engineering, and geotechnical engineering in recent years. The most common ANN used in structural engineering is backpropagation neural network followed by RNN and RBF neural networks. In recent years, newer hybrid techniques have been used in structural engineering by a number of researchers such as the neuro-fuzzy inference system, time-delayed neurofuzzy inference system, and wavelet neural networks. A recent application of deep neural network learning model in construction has been presented in this paper. In addition, Cha et al. [124] presented deep learningbased crack damage detection using convolutional neural network. Other applications of deep neural network learning model should follow.

\section{References}

1. Wang, Z., Guo, L. and Adjouadi, M. "A generalized leaky integrate-and-fire neuron model with fast implementation method", International Journal of Neural Systems, 24(5), 1440004 (15pages) (2014).

2. Deng, Z. and Zhang, Z. "Event-related complexity analysis and its application in the detection of facial attractiveness", International Journal of Neural Systems, 24(7), 1450026 (11 pages) (2014).

3. Palomo, E.J. and Lopez-Rubio E. "Learning topologies with the growing neural forest", International Journal of Neural Systems, 26(3), 1650019 (21 pages) (2016).
4. Khashman, A. and Sekeroglu, B. "Document image binarisation using a supervised neural network", International Journal of Neural Systems, 18(5), pp. 405-418 (2008).

5. Gonzalez, M., Dominguez, D., Rodriguez, F.B. and Sanchez, A. "Retrieval of noisy fingerprint patterns using metric attractor networks", International Journal of Neural Systems, 24(7), 1450025 (13 pages) (2014).

6. Huo, J., Gao, Y., Yang, W. and Yin, H. "Multiinstance dictionary learning for detecting abnormal event detection in surveillance videos", International Journal of Neural Systems, 24(3), 1430010 (15 pages) (2014).

7. Valtierra-Rodriguez, M., Romero-Troncoso, R., Osornio-Rios, R.A. and Garcia-Perez, A. "Detection and classification of single and combined power quality disturbances using neural networks", IEEE Transactions on Industrial Electronics, 61(5), pp. 2473-2482 (2014).

8. Villaverde, I., Grana, M. and d'Anjou, A. "Morphological neural networks and vision based simultaneous localization and mapping", Integrated ComputerAided Engineering, 14(4), pp. 355-363 (2007).

9. Adeli, H., Ghosh-Dastidar, S. and Dadmehr, N. "Alzheimer's disease and models of computation: Imaging, classification, and neural models", Journal of Alzheimer's Disease, 7(3), pp. 187-199 (2005).

10. Bolle, D. and Heylen, R. "Adaptive thresholds for neural networks with synaptic noise", International Journal of Neural Systems, 17(4), pp. 241-252 (2007).

11. Iglesias, J. and Villa, A.E.P. "Emergence of preferred firing sequences in large spiking neural networks during simulated neuronal development", International Journal of Neural Systems, 18(4), pp. 267-277 (2008).

12. Chen, M., Jiang, C.S., Wu, Q.X. and Chen, W.H. "Synchronization in arrays of uncertain delay neural networks by decentralized feedback control", International Journal of Neural Systems, 17(2), pp. 115-122 (2007).

13. Neumann, D., Eckmiller, R. and Baruth, O. "Combination of biometric data and learning algorithms for both generation and application of a secure communication link", Integrated Computer-Aided Engineering, 14(4), pp. 345-352 (2007).

14. Mosavi, M.R. "GPS receivers timing data processing using neural networks: Optimal estimation and errors modeling", International Journal of Neural Systems, 17(5), pp. 383-393 (2007).

15. Christodoulou, M.A. and Kontogeorgou, C. "Collision avoidance in commercial aircraft free fight, via neural networks and non-linear programming", International Journal of Neural Systems, 18(5), pp. 371-387 (2008).

16. Schneider, N.C. and Graupe, D. "A modified lamstar neural network and its applications", International Journal of Neural Systems, 18(4), pp. 331-337 (2008). 
17. Adeli, H. and Yeh, C. "Perception learning in engineering design", Computer-Aided Civil and Infrastructure Engineering, 4(4), pp. 247-56 (1989).

18. Adeli, H. "Neural networks in civil engineering: 19892000", Computer-Aided Civil and Infrastructure Engineering, 16(2), pp. 126-142 (2001).

19. Yuen, K.V. and Mu, H.Q. "Real-time system identification: an algorithm for simultaneous model class selection and parametric identification", ComputerAided Civil and Infrastructure Engineering, 30(10), pp. 785-801 (2015).

20. Zhang, J., Guo, S.L. and Zhang, Q.Q. "Mobile impact testing for structural flexibility identification with only a single reference", Computer-Aided Civil and Infrastructure Engineering, 30(9), pp. 703-714 (2015).

21. Bolourchi, A., Masri, S.F. and Aldraihem, O.J. "Studies into computational intelligence and evolutionary approaches for model-free identification of hysteretic systems", Computer-Aided Civil and Infrastructure Engineering, 30(5), pp. 330-346 (2015).

22. Xu, B., He, J. and Masri, S.F. "Data-based modelfree hysteretic restoring force and mass identification for dynamic systems", Computer-Aided Civil and Infrastructure Engineering, 30(1), pp. 2-18 (2015).

23. Huang, C.S., Hung, S.L., Wen, C.M. and Tu, T.T. "A neural network approach for structural identification and diagnosis of a building from seismic response data", Earthquake Engineering \& Structural Dynamics, 32(2), pp. 187-206 (2003).

24. Hung, S.L., Huang, C.S., Wen, C.M. and Hsu, Y.C. "Nonparametric identification of a building structure from experimental data using wavelet neural network", Computer-Aided Civil and Infrastructure Engineering, 18(5), pp. 356-368 (2003).

25. Zhang, Q. and Benveniste, A. "Wavelet networks", IEEE Transaction on Neural Networks, 3(6), pp. 889898 (1992).

26. Ghodrati Amiri, G., Abdolahi Rad, A. and Khanmohamadi Hazaveh, N. "Wavelet based method for generating non-stationary artificial pulse-like nearfault ground motions", Computer-Aided Civil and Infrastructure Engineering, 29(10), pp. 758-770 (2014).

27. Amini, F. and Zabihi-Samani, M. "A wavelet-based adaptive pole assignment method for structural control", Computer-Aided Civil and Infrastructure Engineering, 29(6), pp. 464-477 (2014).

28. Adeli, H. and Jiang, X. "Dynamic fuzzy wavelet neural network model for structural system identification", Journal of Structural Engineering, 132(1), pp. 102-111 (2006).

29. Jiang, X. and Adeli, H. "Dynamic wavelet neural network for nonlinear identification of highrise buildings", Computer-Aided Civil and Infrastructure Engineering, 20(5), pp. 316-330 (2005).

30. Adeli, H. and Hung, S.L., Machine Learning-Neural Networks, Genetic Algorithms, and Fuzzy Systems, John Wiley and Sons, New York (1995).
31. Forero-Mendoza, L., Vellasco, M. and Figueiredo, K. "Intelligent multiagent coordination based on reinforcement hierarchical neuro-fuzzy models", International Journal of Neural Systems, 24(8), 1450031 (20 pages) (2014).

32. Wang, H. and Shi, X.M. "Hierarchical ANFIS identification of magneto-rheological dampers", Applied Mechanics and Materials, 29, pp. 343-348 (2010).

33. Mitchell, R., Kim, Y. and El-Korchi, T. "System identification of smart structures using a wavelet neuro-fuzzy model", Smart Materials and Structures, 21(11), 115009 (2012).

34. Arsava, K.S., Kim, Y., El-Korchi, T. and Park, H.S. "Nonlinear system identification of smart structures under high impact loads", Smart Materials and Structures, 22(5), 055008 (2013).

35. Zhou, L., Yan, G. and Ou, J. "Response surface method based on radial basis functions for modeling large-scale structures in model updating", ComputerAided Civil and Infrastructure Engineering, 28(3), pp. 210-226 (2013).

36. Khalid, M., Yusof, R., Joshani, M., Selamat, H. and Joshani, M. "Nonlinear identification of a magnetorheological damper based on dynamic neural networks", Computer-Aided Civil and Infrastructure Engineering, 29(3), pp. 221-233 (2014).

37. Cabessa, J. and Siegelmann, H.T. "The super-turing computational power of evolving recurrent neural networks", International Journal of Neural Systems, 24(8), 1450029 (22 pages) (2014).

38. Sun, H., Feng, D., Liu, Y. and Feng, M.Q. "Statistical regularization for identification of structural parameters and external loadings using state space models", Computer-Aided Civil and Infrastructure Engineering, 30(11), pp. 843-858 (2015).

39. Perez-Ramirez, C.A., Amezquita-Sanchez, J.P., Adeli, H., Valtierra-Rodriguez, M., Camarena- Martinez, D. and Rene Romero-Troncoso, R.J. "New methodology for modal parameters identification of smart civil structures using ambient vibrations and synchrosqueezed wavelet", Engineering Applications of Artificial Intelligence, 48, pp. 1-16 (2016).

40. Perez-Ramirez, C.A., Amezquita-Sanchez, J.P., Adeli, H., Valtierra-Rodriguez, M., Romero-Troncoso, R.D.J., Dominguez-Gonzalez, A. and OsornioRios, R.A. "Time-frequency techniques for modal parameters identification of civil structures from acquired dynamic signals", Journal of Vibroengineering, 18(5), pp. 3164-3185 (2016).

41. Siddique, N. and Adeli, H., Computational Intelligence - Synergies of Fuzzy Logic, Neural Networks and Evolutionary Computing, Wiley, West Sussex, United Kingdom (2013).

42. Hung, S.L. and Kao, C.Y. "Structural damage detection using the optimal weights of the approximating artificial neural networks", Earthquake Engineering \& Structural Dynamics, 31(2), pp. 217-234 (2002). 
43. Sun, Z. and Chang, C.C. "Structural damage assessment based on wavelet packet transform", Journal of Structural Engineering, 128(10), pp. 1354-1361 (2002).

44. Su, W.C., Huang, C.S., Chen, C.H., Liu, C.Y., Huang, H.C. and Le, Q.T. "Identifying the modal parameters of a structure from ambient vibration data via the stationary wavelet packet", Computer Aided Civil and Infrastructure Engineering, 29(10), pp. 738-757 (2014).

45. Lee, J.J., Lee, J.W., Yi, J.H., Yun, C.B. and Jung, H.Y. "Neural networks-based damage detection for bridges considering errors in baseline finite element models", Journal of Sound and Vibration, 280(3), pp. 555-578 (2005).

46. Fang, X., Luo, H. and Tang, J. "Structural damage detection using neural network with learning rate improvement", Computers \& Structures, 83(25), pp. 2150-2161 (2005).

47. Lam, H.F., Yuen, K.V. and Beck, J.L. "Structural health monitoring via measured Ritz vectors utilizing artificial neural networks", Computer-Aided Civil and Infrastructure Engineering, 21(4), pp. 232-241 (2006).

48. Ni, Y.Q., Zhou, X.T. and Ko, J.M. "Experimental investigation of seismic damage identification using PCA-compressed frequency response functions and neural networks", Journal of Sound and Vibration, 290(1-2), pp. 242-263 (2006).

49. $\mathrm{Xu}, \mathrm{H}$. and Humar, J. "Damage detection in a girder bridge by artificial neural network technique", Computer-Aided Civil and Infrastructure Engineering, 21(6), pp. 450-464 (2006).

50. Mehrjoo, M., Khaji, N., Moharrami, H. and Bahreininejad, A. "Damage detection of truss bridge joints using artificial neural networks", Expert Systems with Applications, 35(3), pp. 1122-1131 (2008).

51. Li, J., Dackermann, U., Xu, Y.L. and Samali, B. "Damage identification in civil engineering structures utilizing PCA-compressed residual frequency response functions and neural network ensembles", Structural Control and Health Monitoring, 18(2), pp. 207-226 (2009).

52. Samali, B., Dackermann, U. and Li, J. "Location and severity identification of notch-type damage in a two-storey steel framed structure utilising frequency response functions and artificial neural network", Advances in Structural Engineering, 15(5), pp. 743758 (2012).

53. Garcia-Perez, A., Amezquita-Sanchez, J.P., Dominguez-Gonzalez, A., Sedaghati, R., Osornio-Rios, R. and Romero-Troncoso, R.J. "Fused empirical mode decomposition and wavelets for locating combined damage in a truss-type structure through vibration analysis", Journal of Zhejiang University SCIENCE A, 14, pp. 615-630 (2013).
54. Shu, J., Zhang, Z., Gonzalez, I. and Karoumi, R. "The application of a damage detection method using artificial neural network and train-induced vibrations on a simplified railway bridge model", Engineering Structures, 52, pp. 408-421 (2013).

55. Nagpal, T. and Brar, Y.S. "Artificial neural network approaches for fault classification: comparison and performance", Neural Computing and Applications, 25(7-8), pp. 1863-1870 (2014).

56. Jiang, S.F., Fu, C. and Zhang, C. "A hybrid datafusion system using modal data and probabilistic neural network for damage detection", Advances in Engineering Software, 42(6), pp. 368-374 (2011).

57. Zhou, X.T., Ni, Y.Q. and Zhang, F.L. "Damage localization of cable-supported bridges using modal frequency data and probabilistic neural network", Mathematical Problems in Engineering, Article ID 837963, 10 pages (2014).

58. Butcher, J.B., Day, C.R., Austin, J.C. and Haycock, P.W. "Defect detection in reinforced concrete using random neural architectures", Computer-Aided Civil and Infrastructure Engineering, 29, pp. 191-207 (2014).

59. Story, B.A. and Fry, G.T. "A structural impairment detection system using competitive arrays of articial neural networks", Computer-Aided Civil and Infrastructure Engineering, 29(3), pp. 180-190 (2014).

60. Farrokh, M., Dizaji, M. and Joghataie, A. "Modeling hysteretic deteriorating behavior using generalized Prandtl neural network", Journal of Engineering Mechanics, 141(8), 04015024 (10 pages) (2015).

61. Dai, H., Zhang, H. and Wang, W. "A multiwavelet neural network-based response surface method for structural reliability analysis", Computer-Aided Civil and Infrastructure Engineering, 30(2), pp. 151-162 (2015).

62. Jiang, X. and Adeli, H. "Pseudospectra, MUSIC, and dynamic wavelet neural network for damage detection of highrise buildings", International Journal for $\mathrm{Nu}$ merical Methods in Engineering, 71(5), pp. 606-629 (2007).

63. Osornio-Rios, R.A., Amezquita-Sanchez, J.P., Romero-Troncoso, R.J. and Garcia-Perez, A. "MUSICANN analysis for locating structural damages in a truss-type structure by means of vibrations", Computer-Aided Civil and Infrastructure Engineering, 27(9), pp. 687-698 (2012).

64. El-Khoury, O. and Adeli, H. "Recent advances on vibration control of structures under dynamic loading", Archives of Computational Methods in Engineering, 20(4), pp. 353-360 (2013).

65. Brown, A.S. and Yang, H.T. "Neural networks for multiobjective adaptive structural control", Journal of Structural Engineering, 127(2), pp. 203-210 (2001).

66. Jha, R. and He, C. "Design and experimental validation of an adaptive neurocontroller for vibration suppression", Journal of Intelligent Material Systems and Structures, 14(8), pp. 497-506 (2003). 
67. Madan, A. "Vibration control of building structures using self-organizing and self-learning neural networks", Journal of Sound and Vibration, 287(4), pp. 759-784 (2005).

68. Kim, D.H. and Lee, I.W. "Neuro-control of seismically excited steel structure through sensitivity evaluation scheme", Earthquake Engineering and Structural Dynamics, 30(9), pp. 1361-1377 (2001).

69. Wang, D.H. and Liao, W.H. "Modeling and control of magnetorheological fluid dampers using neural networks", Smart Materials and Structures, 14(1), pp. 111-126 (2005).

70. Xu, Z.D. and Guo, Y.Q. "Neuro-fuzzy control strategy for earthquake-excited nonlinear magnetorheological structures", Soil Dynamics and Earthquake Engineering, 28(9), pp. 717-727 (2008).

71. Jiang, X. and Adeli, H. "Dynamic fuzzy wavelet neuroemulator for non-linear control of irregular building structures", International Journal for Numerical Methods in Engineering, 74(7), pp. 1045-1066 (2008).

72. Laflamme, S., Slotine, J.J.E. and Connor, J.J. "Wavelet network for semi-active control", Journal of Engineering Mechanics, 137(7), pp. 462-474 (2011).

73. Wang, N. and Adeli, H. "Self-constructing wavelet neural network algorithm for nonlinear control of large structures", Engineering Applications of Artificial Intelligence, 41, pp. 249-258 (2015).

74. Agrawal, A., Tan, P., Nagarajaiah, S. and Zhang, J. "Benchmark structural control problem for a seismically excited highway bridge-Part I: Phase I Problem definition", Structural Control and Health Monitoring, 16, pp. 509-529 (2009).

75. Hashemi, S.M.A., Haji-Kazemi, H. and Karamodin, A. "Localized genetically optimized wavelet neural network for semi-active control of buildings subjected to earthquake", Structural Control and Health Monitoring, 23(8), pp. 1074-1087 (2016).

76. Joly, M.M., Verstraete, T. and Paniagua, G. "Integrated multifidelity, multidisciplinary evolutionary design optimization of counterrotating compressors", Integrated Computer-Aided Engineering, 21(3), pp. 249-261 (2014).

77. Sirca Jr, G.F. and Adeli, H. "Counterpropagation neural network model for steel girder bridge structures", Journal of Bridge Engineering, 9(1), pp. 55-65 (2004).

78. Jenkins, W.M. "Structural reanalysis using a neural network-based iterative method", Journal of Structural Engineering, 128(7), pp. 946-950 (2002).

79. Garzón-Roca, J., Adam, J.M., Sandoval, C. and Roca, P. "Estimation of the axial behaviour of masonry walls based on artificial neural networks", Computers \& Structures, 125, pp. 145-152 (2013).

80. Adeli, H. and Park, H.S. "A neural dynamics model for structural optimization-theory", Computers \& Structures, 57(3), pp. 383-390 (1995).
81. Adeli, H. and Park, H.S. "Fully automated design of superhighrise building structure by a hybrid AI model on a massively parallel machine", AI Magazine, 17(3), pp. 87-93 (1996).

82. Tashakori, A.R. and Adeli, H. "Optimum design of cold-formed steel space structures using neural dynamic model", Journal of Constructional Steel Research, 58(12), pp. 1545-1566 (2002).

83. Amini, F. and Tavassoli, M.R. "Optimal structural active control force, number and placement of controllers", Engineering Structures, 27(9), pp. 13061316 (2005).

84. Salajegheh, E. and Gholizadeh, S. "Optimum design of structures by an improved genetic algorithm using neural networks", Advances in Engineering Software, 36(11), pp. 757-767 (2005).

85. Gholizadeh, S., Salajegheh, E. and Torkzadeh, P. "Structural optimization with frequency constraints by genetic algorithm using wavelet radial basis function neural network", Journal of Sound and Vibration, 312(1), pp. 316-331 (2008).

86. Salajegheh, E. and Heidari, A. "Optimum design of structures against earthquake by wavelet neural network and filter banks", Earthquake Engineering \& Structural Dynamics, 34(1), pp. 67-82 (2005).

87. Lagaros, N.D., Garavelas, A.T. and Papadrakakis, M. "Innovative seismic design optimization with reliability constraints", Computer Methods in Applied Mechanics and Engineering, 198(1), pp. 28-41 (2008).

88. Salajegheh, E., Salajegheh, J., Seyedpoor, S.M. and Khatibinia, M. "Optimal design of geometrically nonlinear space trusses using adaptive neuro-fuzzy inference system", Scientia Iranica, 16(5), pp. 403414 (2009).

89. Dai, H. and Wang, W. "An adaptive wavelet frame neural network method for efficient reliability analysis", Computer-Aided Civil and Infrastructure Engineering, 29(10), pp. 801-814 (2014).

90. Lee, J. and Shin, K.H. "A conservative method of wavelet neural network based meta-modeling in constrained approximate optimization", Computers \& Structures, 89(1), pp. 109-126 (2011).

91. de Santana Gomes, W.J. and Beck, A.T. "Global structural optimization considering expected consequences of failure and using ANN surrogates", Computers \& Structures, 126, pp. 56-68 (2013).

92. Gholizadeh, S. and Mohammadi, M. "Reliabilitybased seismic optimization of steel frames by metaheuristics and neural networks", ASCE-ASME Journal of Risk and Uncertainty in Engineering Systems, Part A: Civil Engineering, 04016013 (2016).

93. Boulkabeit, I., Mthembu, L., De Lima Neto, F. and Marwala, T. "Finite element model updating using fish school search and volitive particle swarm optimization", Integrated Computer-Aided Engineering, 22(4), pp. 361-376 (2014). 
94. Wu, J.W., Tseng, J.C.R. and Tsai, W.N. "A hybrid linear text segmentation algorithm using hierarchical agglomerative clustering and discrete particle swarm optimization", Integrated Computer-Aided Engineering, 21(1), pp. 35-46 (2014).

95. Shabbir, F. and Omenzetter, P. "Particle swarm optimization with sequential niche technique for dynamic finite element model updating", ComputerAided Civil and Infrastructure Engineering, 30(5), pp. 359-375 (2015).

96. Lee, S.C. "Prediction of concrete strength using artificial neural networks", Engineering Structures, 25(7), pp. 849-857 (2003).

97. Kim, D.K., Lee, J.J., Lee, J.H. and Chang, S.K. "Application of probabilistic neural networks for prediction of concrete strength", Journal of Materials in Civil Engineering, 17(3), pp. 353-362 (2005).

98. Gupta, R., Kewalramani, M.A. and Goel, A. "Prediction of concrete strength using neural-expert system", Journal of Materials in Civil Engineering, 18(3), pp. 462-466 (2006).

99. Pham, T. and Hadi, M. "Predicting stress and strain of FRP-confined square/rectangular columns using artificial neural networks", Journal of Composites for Construction, 18(6), 04014019 (9 pages) (2014).

100. Rafiei, M.H., Khushefati, W.H., Demirboga, R. and Adeli, H. "Neural network, machine learning, and evolutionary approaches for concrete material characterization", ACI Materials Journal (In press).

101. Panakkat, A. and Adeli, H. "Recent efforts in earthquake prediction (1990-2007)", Natural Hazards Review, 9(2), pp. 70-80 (2008).

102. Panakkat, A. and Adeli, H. "Neural network models for earthquake magnitude prediction using multiple seismicity indicators", International Journal of Neural Systems, 17(01), pp. 13-33 (2007).

103. Panakkat, A. and Adeli, H. "Recurrent neural network for approximate earthquake time and location prediction using multiple seismicity indicators", Computer-Aided Civil and Infrastructure Engineering, 24(4), pp. 280-292 (2009).

104. Adeli, H. and Panakkat, A. "A probabilistic neural network for earthquake magnitude prediction", $\mathrm{Neu}$ ral Networks, 22(7), pp. 1018-1024 (2009).

105. Alavi, A. and Gandomi, A. "Prediction of principal ground-motion parameters using a hybrid method coupling artificial neural networks and simulated annealing", Computers and Structures, 89, pp. 21762194 (2011).

106. Brown, A.S., Yang, H.T. and Wrobleski, M.S. "Improvement and assessment of neural networks for structural response prediction and control", Journal of Structural Engineering, 131(5), pp. 848-850 (2005).

107. Fall, H., Guessasma, S. and Charon, W. "Prediction of stability and performance of an active mechanical structure under uncertainty conditions using finite element and neural computation", Engineering Structures, 28(13), pp. 1787-1794 (2006).
108. Dahou, Z., Sbartaï, Z.M., Castel, A. and Ghomari, F. "Artificial neural network model for steel-concrete bond prediction", Engineering Structures, 31(8), pp. 1724-1733 (2009).

109. Petroutsatou, K., Georgopoulos, E., Lambropoulos, S. and Pantouvakis, J.P. "Early cost estimating of road tunnel construction using neural networks", Journal of Construction Engineering and Management, 138(6), pp. 679-687 (2011).

110. de Lautour, O.R. and Omenzetter, P. "Prediction of seismic-induced structural damage using artificial neural networks", Engineering Structures, 31(2), pp. 600-606 (2009).

111. Zhang, Y., Zhou, G.C., Xiong, Y. and Rafiq, M.Y. "Techniques for predicting cracking pattern of masonry wallet using artificial neural networks and cellular automata", Journal of Computing in Civil Engineering, 24(2), pp. 161-172 (2010).

112. Al-Rahmani, A.H., Rasheed, H.A. and Najjar, Y. "Intelligent damage detection in bridge girders: Hybrid approach", Journal of Engineering Mechanics, 139(3), pp. 296-304 (2012).

113. Elshafey, A.A., Dawood, N., Marzouk, H. and Haddara, M. "Crack width in concrete using artificial neural networks", Engineering Structures, 52, pp. 676-686 (2013).

114. Zhang, A. and Zhang, L. "RBF neural networks for the prediction of building interference effects", Computers \& Structures, 82(27), pp. 2333-2339 (2004).

115. Lee, J., Guan, H., Loo, Y.C. and Blumenstein, M. "Development of a long-term bridge element performance model using Elman neural networks", Journal of Infrastructure Systems, 20(3), 04014013 (2014).

116. Freitag, S., Graf, W., Kaliske, M. and Sickert, J.U. "Prediction of time-dependent structural behaviour with recurrent neural networks for fuzzy data", Computers \& Structures, 89(21), pp. 1971-1981 (2011).

117. Patel, D. and Jha, K. "Neural network approach for safety climate prediction", Journal of Management in Engineering, 31(6), 05014027 (11 pages) (2014).

118. Heravi, G. and Eslamdoost, E. "Applying artificial neural networks for measuring and predicting construction-labor productivity", Journal of Construction Engineering and Management, 141(10), 04015032 (11 pages) (2015).

119. Hinton, G.E, Osindero, S. and Teh, Y.W. "A fast learning algorithm for deep belief nets", Neural Computation, 18(7), pp. 1527-1554 (2006).

120. Rafiei, M.H. and Adeli, H. "A novel machine learning model for estimation of sale prices of real estate units", Construction Engineering and Management, 142(2), 04015066 (10 pages) (2016).

121. Tarawneh, B. "Pipe pile setup: database and prediction model using artificial neural network", Soils and Foundations, 53(4), pp. 607-615 (2013). 
122. Araei, A. "Artificial neural networks for modeling drained monotonic behavior of rockfill materials", International Journal of Geomechanics, 14(3), 04014005 (15 pages) (2014).

123. Shahin, M. "Load-settlement modeling of axially loaded drilled shafts using CPT-based recurrent neural networks", International Journal of Geomechanics, 14(6), 06014012 (7 pages) (2014).

124. Cha, Y.J., Choi, W. and Buyukozturk, O. "Deep learning-based crack damage detection using convolutional neural network", Computer-Aided Civil and Infrastructure Engineering, 32(3) (2017, to be published).

\section{Biographies}

Juan P. Amezquita-Sanchez graduated from University of Guanajuato in 2007 with a BSc Degree in Electronic Engineering. He received his MSc degree in Electrical Engineering from University of Guanajuato and the $\mathrm{PhD}$ degree in Mechatronics from the Autonomous University of Queretaro, Queretaro, Mexico, in 2009 and 2012, respectively. He was a Postdoctoral Visiting Scholar in The Ohio State University during 2013-2014. He is currently an Assistant Professor at the Faculty of Engineering, Autonomous University of Queretaro, Campus San Juan del Rio, Queretaro, Mexico. He is a member of the Mexican National Research System (SNI), level 1. He has published in the areas of structural health monitoring, signal processing, and mechatronics.

Martin Valtierra-Rodriguez received the BE degree in Mechatronics Engineering and the ME degree in Electrical Engineering from the University of Guanajuato, Guanajuato, Mexico, in 2008 and 2010, respectively, and the PhD degree in Mechatronics from the Autonomous University of Queretaro, San Juan del Río, Mexico, in 2013. He is currently a Professor with the Faculty of Engineering, Autonomous University of Queretaro and a member of the Mexican National Research System (level 1). His current research interests include signal processing, expert systems, and applications of mechatronics.

Mais Aldwaik received her Bachelor and Master's degrees from the University of Jordan in 2006 and 2012, respectively. She worked as a Structural Engineer from 2006 to 2011. She is currently a PhD Candidate in the Department of Civil, Environmental, and Geodetic Engineering at The Ohio State University. She has done research and published in the areas of reinforced concrete structures and design optimization.

Hojjat Adeli is a Professor of Civil, Environmental, and Geodetic Engineering at The Ohio State University. He has authored over 540 research publications including 15 pioneering computational books, since he received his $\mathrm{PhD}$ from Stanford University in 1976 at the age of 26 . In 1998, he received the University Distinguished Scholar Award from The Ohio State University "in recognition of extraordinary accomplishment in research and scholarship." Among his numerous other awards and honors are the Lumley Research Award in Recognition of Outstanding Research Accomplishments (quadruple winner), Peter L. and Clara M. Scott Award for Excellence in Engineering Education, Charles E. MacQuigg Outstanding Teaching Award from OSU, a Special Medal in Recognition of Outstanding Contribution to the Development of Computational Intelligence from the Polish Neural Network Society, the Eduardo Renato Caianiello Award "for Having Realized the Model of Interdisciplinary Scientist in the Pursuit of E.R. Caianiello Project and for the Excellent Results in Engineering and Neuroscience," from the Italian Society of Neural Networks, an Honorary Doctorate from Vilnius Gediminas Technical University, Lithuania, and membership in the Spanish Royal Engineering Society. He received the ASCE Construction Management Award in 2006. In 1998, he was awarded a United States patent for his neural dynamics model for design automation and optimization (jointly with a former $\mathrm{PhD}$ student). He is a Distinguished Member of ASCE, and a Fellow of AAAS, IEEE, AIMBE, and the American Neurological Association. 